\title{
Activity Based Quality Model for Evaluating Web2.0 Applications
}

\author{
Ambreen Nazir \\ Department of Software Engineering, University of Engineering and Technology, Taxila, Pakistan \\ Email: ambreen_nazir_ms@yahoo.com \\ Ayesha Raana \\ Department of Software Engineering, University of Engineering and Technology, Taxila, Pakistan \\ Email: ayesha.raana@yahoo.com \\ Ali Javed \\ Department of Software Engineering, University of Engineering and Technology, Taxila, Pakistan \\ Email: ali.javed@uettaxila.edu.pk
}

\begin{abstract}
Quality is key term to be considered when developing the Web applications. If this is not adequately measured; there will be little to force users to use web applications. The focus of Web2.0 is to enhance the interactions between the application and end users and among users. The main challenge of this research is to identify the key quality attributes that gain the end user attention towards the Web applications. There are many Quality Models available for measuring the W2A (Web2.0 Applications). This paper has a critical review of the previously defined quality models. It defines a theoretical quality model containing essential attributes to assess the quality of W2A.
\end{abstract}

Index Terms - Attributes, End User, Interaction, Quality Model, W2A

\section{INTRODUCTION}

Now a day's Internet has become the backbone of every field. Over the last years, Web development is affecting the society from all aspects i.e. business environment, educational field, communicating ways between people. Early Web development was known as Web1.0 and after it, Web2.0 has come into view. It reflects on a set of plans, new emerging technologies, socialism, togetherness and individualization. Years ago, during a brainstorming session between Tim O'Reilly and Dale Dougherty [1] the conception of Web 2.0 was fictitious. Web2.0 is all concerning, binding and collecting the intellectual data at one place. Basically, Web 2.0 is a logical step in platform maturation, as it evolves the form of publishing the information from the traditional style to an interactive and dynamic medium where the content creation process is handled by all the users.

W2A are launching day by day. These applications need to provide the relevant, appropriate, secure and quality in use functions and contents that help in delivering the intended goals and tasks of them. Software quality is measured as how much unique and function oriented a product is to satisfy individual desires, same like the total quality assessment of Web2.0 depends on many attributes, user experience and data that is feeding the W2A, most important, how happy the end user to use the web application. Users expect the functions and contents of W2A be pertinent, legitimate, convenient and eventually with perceived quality.

Certainly, all the W2A are dynamic in nature and their evolution is always need to be considered, for that reason it is essential to constantly scrutinize their quality. A good Quality Model can act as a powerful tool in all phases of a W2A life cycle. Quality Model helps in gathering and arranging the requirements in an arranged order, further it helps in describing all the important features of the websites that have to be designed. It assists the development and project team in implementing all the necessary and desired attributes and helps the management team to keep the evolution of their application on the right path by providing them with a limited extent. A Quality Model also allows the evaluators to assess any existing website or to perform the comparison of different website. With the aim of maintaining the quality of W2A, there is a need of a good Quality Model [2] that plays a tremendous role in levying W2 A quality through all perspectives.

This paper comprises of eight sections. In Section II, critical review of the previous work done in the field of Web quality is given. In Section III, all the features of W2A are mentioned. In Section IV, we have suggested seven main quality dimensions in our quality model for the appraisal of W2A quality. In Section V, we have taken into consideration all the necessary quality attributes those clearly and precisely measures all sources of perception of Web usability and quality. In Section VI, Quality metric for each given attribute has given. In Section VII, we have conducted an experimental research study for confirming the internal 
consistency of each attribute and in Section VII closing remarks are given sustaining future research instructions.

\section{LITERATURE REVIEW}

A quality model [2] allows appraisers to evaluate web resources from different viewpoints by providing them the structured set of quality attributes. Previous work on Web quality is incredible and detailed. In the current era the craving for the $\mathrm{W} 2 \mathrm{~A}$ raised beyond the limits, so the requirement of uniqueness with high level quality and to make Web sensational badly become a need. In recent years, researchers have been working on improving the W2A quality by proposing different models and techniques and by defining different methodologies. Firstly, they spent time on simple W2A [3] now they are moving towards advanced applications.

Different quality models are present for W2A [4] [5] and "End User Feedback" plays a real role in improving W2A quality. Over the years many Quality Models have been proposed by different researchers and experts, all of them trying to approach the dilemma from different perspectives. Nakwichian and Sunetnanta [6] offered a model in which users' feedback was considered and was made under ISO/IEC 9126 and IEEE 1061 standards. This model enabled them to evaluate website quality by getting response from different groups of users. They designed a common process for enhancing W2A and provide some instructions that should be followed while assessing any website.

Layla Hasan and Emad Abuelrub [7] proposed a measurable, theoretical and all-purpose framework for estimating quality of any website service without considering the nature and benefit it provide to support the design and implementation techniques of W2A. The objective of their research is to make a website useful, advantageous and user centric. They proposed 4dimensions criteria which are comprehensive Content Quality, Design Quality, Organization Quality and Userfriendly Quality. To recognize the measureable main features and pointers of W2A was the main objective of the researchers.

Luis Olsina, Roberto Sassano, Luisa Mich [8] proposes an integrated approach that identifies the quality of any information provided by W2A. For W2A they highlighted some features, namely: User generated content, User active involvement, Sharing information, and Endless beta condition. The quality Model ISO 9126-1 standard differentiate among three different approaches to software product quality, viz. internal quality, external quality, and quality in use. According to researchers standard characteristics are not well suited to specify requirements for information quality. So to evaluate W2A quality they introduced a new attribute named content quality, to discover whether the text information available on the Websites is free of errors, correct according to the context, comprehensive and fulfills any standard criteria.
Tihomir Orehovacki [9] provides the theoretical basis for the development of a set of attributes that should be considered when measuring the quality of W2A from both technology and user-focused viewpoints. The researcher focused on to find key attributes that will keep users on a Web application for a long time and encourage them to visit it again. He proposed attributes for W2A victory that are addressed via six major categories named as System Quality, Service Quality, Information Quality, Performance, Effort and Acceptability. Further he carried out the assessment of proposed attributes via Inspection Methods (Heuristic Evaluation) and Test Methods (Questionnaire) to ensure that a Web application has the appropriate attributes that will positively affect the experience of its use.

Roberto Polillo [10] discussed a procedural approach for any kind of website. Their approach includes a practical quality model that helps in eliciting user needs and also acts as a tool to maintain quality of W2A during all phases of development life cycle. Therefore, he considered organization mapping to be main driver for definition of any Quality Model, as it distributes the responsibility of managing quality of W2A among actors. Researcher proposed a simple Quality Model and mapped each component of it to a specific actor. The characteristics of the proposed Quality Model which refers to the quality with surroundings and quality in use are Architecture, Communication, Functionality, Content, Community, Platform, Accessibility, Usability and Coding. These characteristics are mapped to the following actors Web Designer, Visual Designer, Function Designer, Software Developer, Content Editor, Community Manager, Usability Professional and Web Master \& Data Center Manager.

Tihomir Orehovacki, Andrina Granic, and Dragutin Kermek [11] discussed quality in use on mind mapping services for W2A. Their assessing methodology came up with harmonizing methods. These are Logging Actual Use Method, Retrospective Thinking Aloud and Questionnaire. They measured estimated quality in use by using first method while the perceived quality in use was evaluated with both remaining methods. After that they developed a conceptual method, along with a number of attributes, which plays a major role for quality and usability assessment of W2A. They organized quality attributes into several categories: These are System Quality, Service Quality, Information Quality, Effort, and Acceptability. They applied the proposed model on a Web application to get an estimate that how effective is their model and also they wanted to discover the importance of user-centric attributes.

Rajeev Saha and Sandeep Grover [12] in their research represented the W2A quality with the help of graph theory and matrix method and the calculated result was shown by a single numeric index. They proposed a useful tool that website designers and developers can use to examine the effectiveness of variables that are accountable for W2A quality. Results in a measureable quantity facilitates in getting the understanding of 
several dimensions and also an effective aid for determining the underlying factors in Web2.0 environments.

\section{KEY FEATURES OF W2A}

For proposing a quality model for assessing the quality of W2A, it is a precondition to discover all the key features of them. From our thorough study from different references [1] [13], we have identified some key features. Fig. 1 shows all the identified key features.

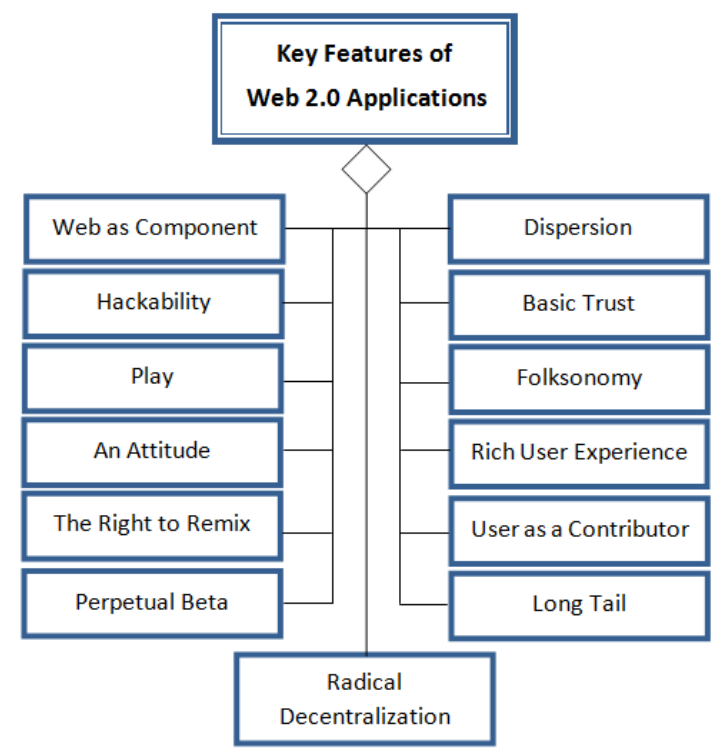

Figure 1. Key Features of W2A

Web as Component [14]: Components do not have to shorten into a massive stone any longer to amalgamate well with one another is the real appeal of W2A. In fact, in new Web platform all small pieces (components) are loosely joined where all the independent component providers will be able to flourish in conjunction with the platform vendors. When the coupling between the components is less, it will be much easy to render the unnecessary components.

Radical Decentralization [15]: In the past trend, all the functionality that was provided by Web application was centralized. Website content was supposed to change and update by a single owner due to which the content quality was decreasing. In Web2.0, radical decentralization act as a pillar where web content is rationalized by different individuals.

Hackability [16]: Web2.0 allows user to modify its application in a way that is not intended by the application owner. Users can participate, create and invent new ways of using W2A by using their abilities instead of just consuming passively.

Play [17]: Web2.0 uses Play Framework to build the applications with Java \& Scala. Play is based on an architecture that is lightweight, stateless and Webfriendly. It also consumes minimum resources (CPU, memory, threads) for highly-scalable application that makes much easy to use W2A.

An Attitude [18]: Web2.0 is about attitude more willingly than an expertise, emerging new concepts are enabled by technology but going beyond technology. It facilitates and promotes participation through open applications and services. It introduces new ways of interaction with all stakeholders, customers, employees, and partners. It also helps in bringing together disparate resources to create new insights.

The Right to Remix [19]: It's been much too long; we leap from a vicinity of the web to another, having trouble with different interfaces, ignoring endless advertisements and facing difficulty in finding the content you need, locating a service, document or a piece of information that congregates our needs.

Perpetual Beta [15]: Perpetual Beta is actually application in which we constantly take users feedback hence considering them a team of us for making alterations to our application. Facebook [20], a well known and popular website, is a live example of perpetual beta. It keeps on releasing new versions or updates of their site after gathering input from the users which gives the developer the chance to improve the application easily after seeing user experience.

Dispersion [21]: In Web2.0 dispersion phenomena is about delivering the content by using multiple channels include permalinks and file sharing instead of using typical method of delivering content as direct site to home. Examples of dispersion include Bit Torrent and Mashup.

Basic Trust [22]: It is about trusting the community and end users. In traditional Web the contents are protected under Intellectual Property Rights but in W2A content are made available to salvage, distribute and edit. Web2.0 helps in keeping open contribution and participation working. Wikipedia is a common example.

Folksonomy [23]: Web2.0 allows user to create free organization of information without following any existing framework of classification. It also helps in finding information. This practice of hunting and classifying information is also known as tagging. Typical example is photo sharing site "Flickr".

Rich User Experience [24]: In general, it is a mixture of Graphical User Interface (GUI) and multimedia content. Web2.0, instead of offering static pages, presents dynamic pages and the key component that makes this easy is Asynchronous JavaScript + XML (AJAX). AJAX technology is highly based upon the idea of semantic markup languages that help users to expand their user experience visually and functionally.

User as a Contributor [21]: The information model in Web2.0 is not one way, rather it is participative. Users can also supply content on the sites by different means such as evaluation, commenting and feedback, so it is not only the site owner who is providing the 
information. W2A are quick in spotting the value of user-generated content. Typical examples are Wikipedia and Youtube.

Long Tail [25]: In Web2.0, the focused product is not selling directly but the owner offers it as a service on demand basis and revenue is generated as a monthly or yearly fee and pay per consumption thus enabling the benefit from key pieces of the platform while fulfilling their own need. In some cases trial version of the product for certain days is offered to the users and then they have to buy the licensing module to keep on using the service.

\section{Dimensions For Assessing The QuAlity OF W2A}

Keeping literature review as our foundation, it is possible to recapitulate the deficiencies of previous approaches for judging the quality of W2A. Most of them don't have a good empirical validation; those approaches do not cover up all the areas of W2A quality and the relationship between the quality attributes; proper guidelines for the use of these approaches are not given as well as they didn't aim general users; there is no definite verification that the existing methodologies and approaches are suitable for estimating the quality of W2A. Therefore, these apparently separate frameworks were combined and a new enhanced model is shaped by keeping the features of Web2.0 in mind that are mentioned in Fig. 1. According to new model, W2A quality can be deal with seven major dimensions which are shown in Fig. 2.

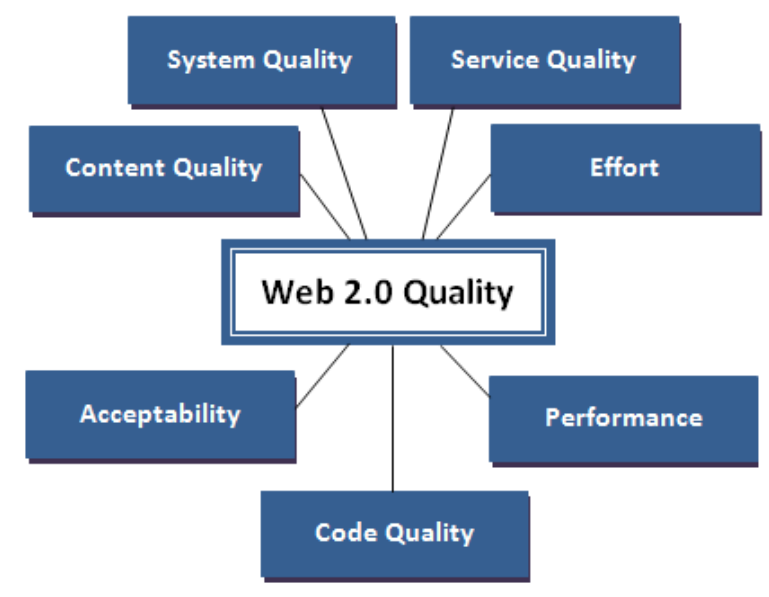

Figure 2. Quality Dimensions for W2A

\section{ACTIVITY-B ASED MODEL FOR ASSESSING THE QUALITY OF W2A}

\section{(PROPOSED CLASSIFICATION OF QUALITY ATTRIBUTES )}

Quality attributes are categorized into mentioned seven dimensions and briefly discussed. Fig. 3 shows the graphical representation of this model.

\section{A. System Quality}

This dimension consists of quality attributes that deals with the level of system functionality and measures quality in use of the interface features of W2A. It includes Functionality (Capability of application to provide features to fulfill the customer's requirements well. Further, functionality has quality criteria that are Accuracy (Degree to measure how much the software application is providing required results), Suitability (Degree to measure the quality of appropriate and a right set of functions for specified tasks), Interoperability (Degree to measure the ability of a system to interact with external environment such as other systems, hardware components etc, without special efforts done by the user) and Confidentiality (Ability of an application not to share the sensitive information to any unauthorized person)), Navigability (Degree to measure the ability of application to perform switching between the application's functional controls), Consistency (Degree to measure that there should be no conflicts or contradictions in the system functions), Aesthetic (Ability of application to be internally beautiful in terms of work well, cost less, have fewer bugs, run faster, match user needs and easier to fix), Familiarity (Level of information, user have about the application controls/functions), Customizability (Ability of commercial application to be modified according to the individual requirements of customer) and Security (Ability of application to protect assets and prevent disclosure/modification of information due to malicious actions outside of the designed usage).

\section{B. Service Quality}

This dimension consists of quality attributes that defines the extent of quality of attraction among Web applications and end users. It includes Helpfulness (Degree to measure how application is providing help content and self explanatory to the user), Availability (Degree to measure which services are available in operational status), Interactivity (Degree to measure the involvement of user with application while performing functions (feel of use)), Error Prevention (Attribute for preventing faults from being injected in the application), Reliability (Degree to measure the level of risk, potential downtime and failures of application), Recoverability (Capability of application to recover the affected data and perform the functionality well after failure and measure how much effort needed for it), Responsiveness (Measure how rapidly W2A react to user calls and commands), Fault Tolerance (Capability of application to perform its functions well even in the presence of faults), Maturity (Degree to measure the failure rate of software due to faults) and Feedback (Measure the ability of a Web application to show its condition and progress at any moment, like the improvement of any activity while executing, send notifications after completing activities etc). 


\section{Content Quality}

This dimension can be measured from two aspects. First is the arising of the information content quality from the use of the Web applications and second is the information text quality which is placed on the W2A. This dimension is decomposed into Correctness (Attribute of application to measure the extent to which it satisfies the requirements. Information content should be free of errors), Coverage (Measure that the information content is suitable, comprehensive and trimly signified), Credibility (Information content is reliable, impartial and confirmable), Timeliness (Ability of application to provide the information content that is state-of-the-art), Value-Added (Degree to which the information content is new and beneficial), Suitability (Attribute highlights the significance of delivering the appropriate information for user oriented goals and tasks) and Content Legal Compliance (Ability of a W2A to hold to standards, principles and officially authorized rules associated with content).

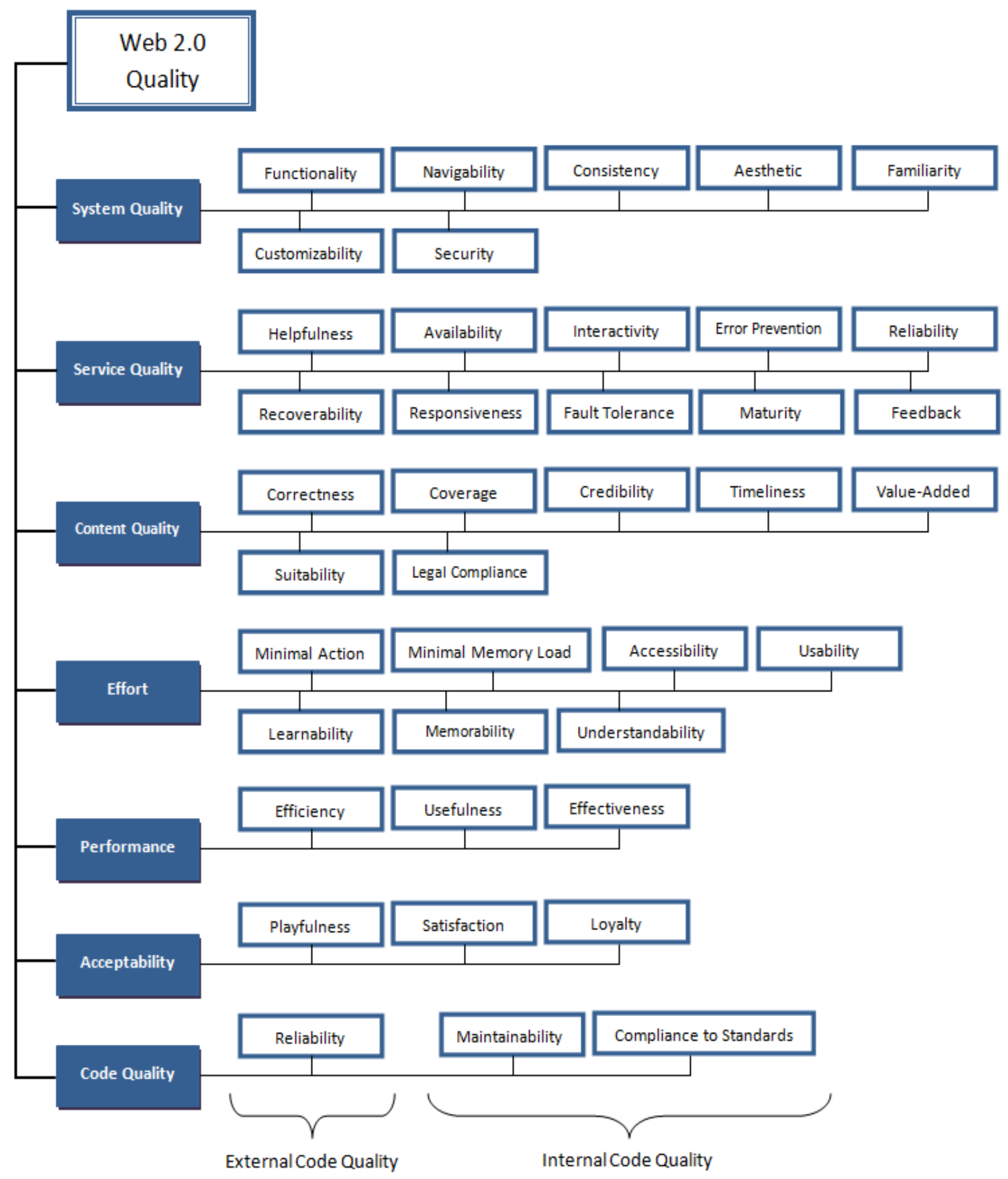

Figure 3. Activity-Based Model for Evaluating the Quality of W2A 


\section{Effort}

This dimension refers to the amount of supposed and estimated psychological and bodily energy when using a W2A. It includes Minimal Action (Ability of W2A that helps users to complete their tasks efficiently in a least possible steps), Minimal Memory Load (Refers to the information that is essential for the users to remember before performing the tasks on the Web application), Accessibility (Measure the probability of availability of specified functions to end users for performing activities are present on the screen), Usability (Degree to measure the usefulness of software functions and how easy user interfaces are to use. Further, usability has quality criteria which are Ease of Use (Degree to measure the extent to which the users are able to perform the actions without any external help content), Operability (Degree to measure the user's effort for operational control of Web application), Level of Communication (Degree to measure the extent to which the Web application captures the users interest in brief time intervals) and Attractiveness (Degree to measure how natural is the application is to be used)), Learnability (how effortless for the user to perform basic functionalities of W2A), Memorability (Degree to measure the level of Web application features to be in mind even someone using the software after a long time) and Understandability (Measure that fundamentals of W2A interface, functionalities and the logical concepts are understandable and unambiguous to the user).

\section{E. Performance}

This dimension brings up the quality of executing activities via the functionalities of W2A interface. This dimension includes Efficiency (Attribute of Web application to measure the speed, amount of resources used and total time required to perform a specified task without affecting the performance rate. Efficiency also includes quality criteria that are Time Behavior (Attribute of an application to measure the response time of average rate of successful functionalities performed), Resource Utilization (Attribute of an application to measure the amount and duration of resources in performing its functions), Scalability (Attribute of an application to measure the extent to handle the increased load without affecting performance), Visibility (Ability to take out useful information from an application artifact. It measures that the processes are externally visible) and Flexibility (Ability of an application to fit in an environment which is not exclusively designed for it)), Usefulness (Extent to which the application is fulfilling the user needs, that the use of the W2A increases the quality of the activity performance) and Effectiveness "resulting performance in relation to effort" (Measure how accurately and completely activities can be performed by using the functionality of Web application interfaces).

\section{E. Acceptability}

This dimension refers to the quality attributes that play a major role for Web application to be successful. It includes Playfulness (Extent to which a Web application has added amenities owing to which the execution of activities is interesting, exciting and motivating), Satisfaction (Attribute according to which a Web application can meet all the customer need with all its capabilities. It measures the ease and comfort through which the Web application makes available to the users) and Loyalty (Measure how the person feels about the completed tasks. Is the person confident or stressed? Would the user recommend this system to a friend? It represents the users' intention that whether he/she wants to continue to use the Web application for performing activities or not).

\section{F. Code Quality}

This dimension brings up the quality of application specifically developed like the quality of any application depends on it code. This dimension includes Reliability (Degree to measure the level of risk, potential downtime and failures of application. It contributes to the external quality of the code), Maintainability (Ability of an application to measure the degree of ease when accumulating or altering the functionality or fixing errors. It contributes to the external quality of the code. It includes further sub-attributes that are Analyzability (Measure the effort needed for diagnosis failures causes, or recognition of element to be customized), Changeability (Measure the exertion needed for alteration, error removal or adapting new environment), Stability (Measure the unexpected effect of modification in the functionality), Testability (Measure the effort required testing a program to ensure that it performs its intended functions) and Modularity (Measure the level of independence between the system modules) and Compliance to Standard (Ability of W2A to remain stick to standards, principles and officially authorized rules linked to the code).

\section{QUALITY METRICS}

In order to get the results of quality attributes in qualitative and quantitative manner, we use a standard of measurement called quality metric. In this section, we have defined metrics for each quality attribute including formula/question/statement. Table 1 shows the quality metric for the given attributes.

TABLE I. QUALITY METRICS FOR QUALITY ATTRIBUTES

Quality Attribute Quality Metric

System Quality

\begin{tabular}{|l|l|}
\hline Functionality & $\begin{array}{l}\text { Perentage of computed } \\
\text { requirements. } \\
\text { Weight of total defect backlog }\end{array}$ \\
\hline $\begin{array}{l}\text { Total mo, of Requirements } \\
\text { Does it interact with other } \\
\text { components. } \\
\text { No. of authorized persons. }\end{array}$ \\
\hline
\end{tabular}




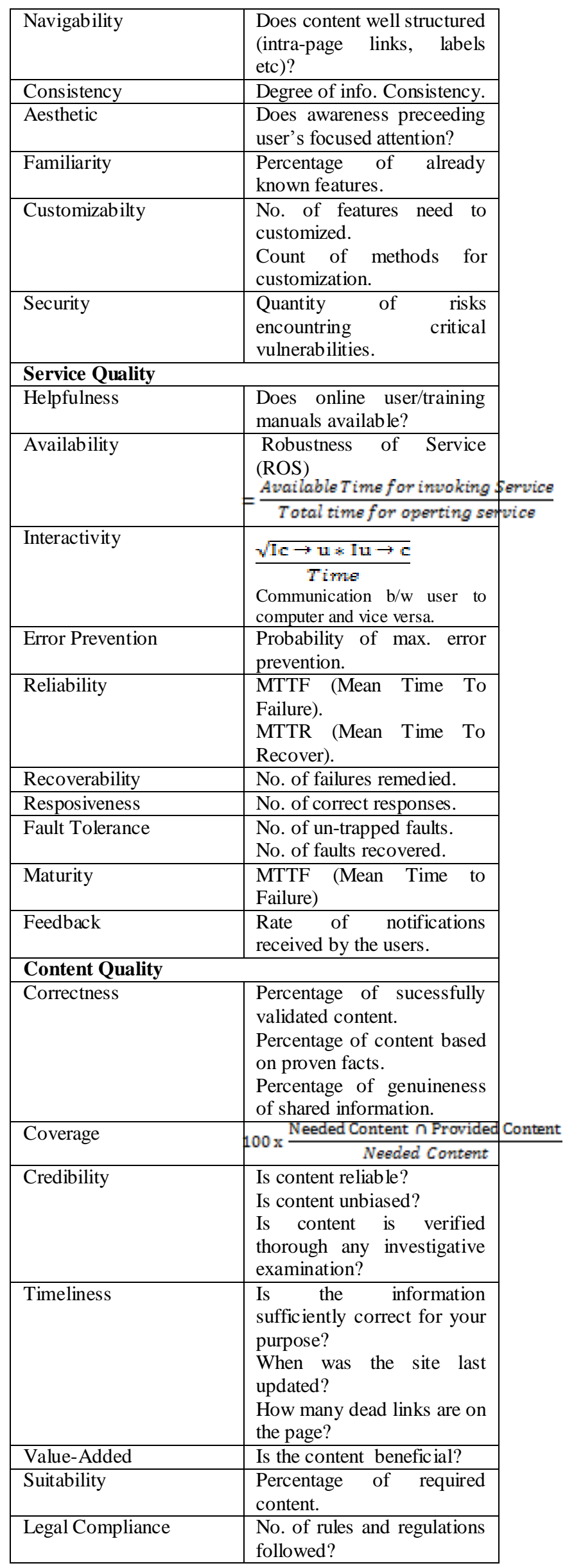

\begin{tabular}{|c|c|}
\hline & $\begin{array}{lll}\text { Does it adhere } & \text { any } \\
\text { standard? } & & \\
\end{array}$ \\
\hline \multicolumn{2}{|l|}{ Effort } \\
\hline Minimal Actions & $\begin{array}{l}\text { No. of mouse clicks } / \\
\text { keyboard inputs. }\end{array}$ \\
\hline Minimal Memory Load & $\begin{array}{l}\text { Visual Designing of the } \\
\text { interface. } \\
\text { Depends on person skills } \\
\text { and abilities. }\end{array}$ \\
\hline Accessibility & $\begin{array}{l}\text { Percentage of max. } \\
\text { functions on the current } \\
\text { screen for performing } \\
\text { particular activity. }\end{array}$ \\
\hline Usability & $\begin{array}{l}\text { Is it easy to comprehend the } \\
\text { content? } \\
\text { Is functionality easy to use? } \\
\text { Measure of effic iency and } \\
\text { productivity. } \\
\text { Completion rate of tasks. } \\
\text { No. of unintended actions? } \\
\text { Single Usability Metric }\end{array}$ \\
\hline Learnability & $\begin{array}{l}\text { Does online help available? } \\
\text { Does user guide complete? }\end{array}$ \\
\hline Memorability & $\begin{array}{l}\text { Is the interface interactive? } \\
\text { No. of features already } \\
\text { known by the user. }\end{array}$ \\
\hline Understandability & $\frac{\text { Features wnderstood byusers }}{\text { Total features }}$ \\
\hline \multicolumn{2}{|l|}{ Performance } \\
\hline Efficiency & $\begin{array}{l}\text { Total execution time. } \\
\text { Amount of allocated } \\
\text { resources. } \\
\text { Total no. of utilized } \\
\text { resources for } 1^{\text {st }} \text { request. }\end{array}$ \\
\hline Usefulness & $\begin{array}{l}\text { No. of total user's need. } \\
\text { No. of needs fulfilled after } \\
\text { performimg single activity. }\end{array}$ \\
\hline Effectiveness & $\begin{array}{l}\text { (No. of tasks completed * } \\
\text { Quality of Goals Achieved) / } \\
100\end{array}$ \\
\hline \multicolumn{2}{|l|}{ Acceptability } \\
\hline Playfulness & $\begin{array}{l}\text { Is the applicaton } \\
\text { interesting? } \\
\text { Is it motivate the user? }\end{array}$ \\
\hline Satisfaction & $\begin{array}{lr}\text { Five Point Scale } & \text { (Very } \\
\text { Satsified, Satisfied, Neutral, } \\
\text { Dissatisfied, } & \text { Very } \\
\text { Dissatisfied) } & \end{array}$ \\
\hline Loyalty & No. of net promoter score. \\
\hline \multicolumn{2}{|l|}{ Code Quality } \\
\hline Reliability & $\begin{array}{l}\text { No. of broken lines. } \\
\text { No. of executable lines. }\end{array}$ \\
\hline Maintainability & 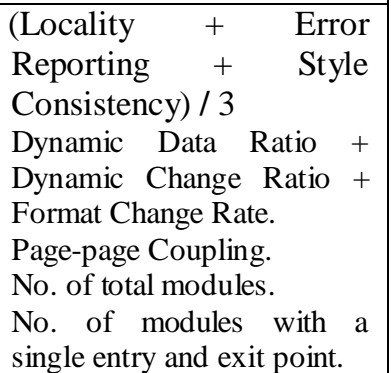 \\
\hline Compliance to Standards & $\begin{array}{l}\text { SLOC (Source Line of } \\
\text { Code) } \\
\text { KLOC (Kilo Line of Code) }\end{array}$ \\
\hline
\end{tabular}


The usability and practicability of proposed quality metrics are assessed by the criteria (Correlation, Tracking, Consistency, Predictability, Discriminative Power, Reliability) defined in IEEE 265 std 1061-1998 [26].

\section{PRELIMINARY RESEARCH RESULTS}

In order to validate the proposed set of dimension in the quality model, we perform user testing by the use of questionnaires and checklist. However, in the literature there are several checklists for user satisfaction and quality of Web pages assessment like UWIS [27], EUCS [28] and PWQ [29] as well as for system quality assessment like SUMI [30] and QUIS [31]. In our case, we focused on usability and quality assessment in particular; data is gathered from representative users in sensible circumstances. Therefore, the member in the study was about 100 undergraduate students of Software Engineering who use W2A for performing different activities and communication (twice a day). The research study was carried out with three W2A: Google Docs for taking notes and Creately [32] and yUML [33] for making different UML diagrams online.

After 90 days, members received the checklists that contain quality related questions. They were supposed to answer the question by using the scale point (1 to 5.1 for high and 5 for low). It took almost 40 minutes to answer all the questions from the checklist. Developer was present to answer the questions of the checklist for code quality dimension. The internal consistency for each quality dimension is assessed by using Cronbach's alpha [34] Results are shown in Table 2. In Table CS is used for Content Sharing (Google Docs) and DC is used for Diagram Creator (yUML).

TABLE II. INTERNAL CONSISTENCY OF QUALITY SCALES

\begin{tabular}{|l|c|c|c|}
\hline \multirow{2}{*}{$\begin{array}{c}\text { Quality } \\
\text { Dimensions }\end{array}$} & \multirow{2}{*}{$\begin{array}{c}\text { No. of } \\
\text { Quality } \\
\text { Attributes }\end{array}$} & \multicolumn{2}{c|}{$\begin{array}{c}\text { Cronbach's } \\
\text { Alpha }\end{array}$} \\
\cline { 3 - 4 } & & CS & DC \\
\hline System Quality & 7 & .814 & .753 \\
\hline Service Quality & 10 & .810 & .802 \\
\hline Content Quality & 7 & .781 & .751 \\
\hline Effort & 7 & .901 & .800 \\
\hline Performance & 3 & .788 & .701 \\
\hline Acceptability & 3 & .901 & .835 \\
\hline Code Quality & 3 & .902 & .899 \\
\hline
\end{tabular}

According to research Google Docs performs all the e-activities more efficiently but overall these Web applications allow users to perform their tasks smoothly.

\section{CONCLUSIONS AND FUTURE WORK}

Web2.0 facilitates users to look at their everyday life in new and innovative ways. W2A rely sturdily on authentic user's contribution, togetherness, cooperation and comply with activities in actual perspective of use.
So evaluating the quality of W2A is still or even more challenging and important activity.

The objective of this research is to define a methodology that helps in assessing the quality of Web2.0. After reviewing different already available evaluation methods/models, this paper proposed a model that unites the power of Web2.0 users and applications so as to improve quality in every dimension and provide a confidence that quality of Web applications always reach a high level.

First, we took out different features of Web2.0 from different links/references. After that, we proposed seven dimensions that are necessary for the assessment of W2A. Then we proposed a set of quality attributes for each dimension. With the help of these dimensions and quality attributes a quality model was designed for W2A. We defined quality metric for each proposed quality attribute and in the end performed a preliminary research study in which we use a technique of test methods called questionnaire, internal consistency is assessed by using Cronbach's Alpha.

We believe that the proposed quality attributes, model and metrics are meaningful for quality judgments of W2A. These cover all the essential features of W2A and offer a manner to evaluate the W2A quality in both qualitative and quantitative way.

Future recommendation will be the experimental investigation of the importance of the proposed attributes and their relationships. We can also make further modifications in this quality model to use it for automated quality measurement of W2A.

\section{REFERENCES}

[1] Tim O'Reilly, "What Is Web2.0? Design Patterns and Business Models for the Next Generation of Software", http://oreilly.com/web2/archive/what-isweb-20.html, October 2009.

[2] Durgesh Samadhiya, Su-Hua Wang, IEEE Xplore, "Quality Models: Role and Value in Software Engineering", 2010.

[3] Melody Y. Ivory, Rodrick Megraw, "Evolution of web site design patterns", http://dl.acm.org/citation.cfm?id=1095876, October 2005.

[4] Dr. Luis Olsina "Evaluating the Quality of Web2.0 Applications",

http://icwe2009.webengineering.org/material/ICWE 09_TutorialOlsina.pdf, 2009.

[5] Tomá `s Knap, Irena Mlýnková, “Quality Assessment Social Networks: A Novel Approach for Assessing the Quality of Information on the Web",

http://www.vldb2010.org/proceedings/files/vldb_20 10_workshop/QDB_2010/Paper1_Knap_Mlynkova. pdf, 2010 . 
[6] S. Nakwichian and T. Sunetnanta, "User-Centric Web Quality Assessment Model", Proceedings of the 7th National Computer Science and Engineering Conference, (NCSEC2003), Thailand, 28-30 October, 2003.

[7] Layla Hasan, Emad Abuelrub, Sciecnce Direct, "Assessing the quality of web sites”,,http://www.sciencedirect.com/science/article/ pii/S2210832710000037, 2008.

[8] Luis Olsina, Roberto Sassano, Luisa Mich, "Towards the Quality for Web2.0 Applications", http://ceur-ws.org/Vol-493/iwwost2009-olsina.pdf, 2009.

[9] Tihomir Orehovacki, IEEE Xplore, "Proposal for a Set of Quality Attributes Relevant for Web2.0 Application Success", 2010.

[10]Roberto Polillo, "Quality Models for Web [2.0] Sites: a Methodological Approach and a Proposal", http://gplsi.dlsi.ua.es/congresos/qwe11/fitxers/QWE 11_Polillo.pdf, 2011.

[11]Tihomir Orehovački, Andrina Granić, Dragutin Kermek, "Exploring the Quality in Use of Web2.0 Applications: The Case of Mind Mapping Services", http://gplsi.dlsi.ua.es/congresos/qwe11/fitxers/QWE 11_Orehovacki.pdf, 2011.

[12]Rajeev Saha, Sandeep Grover, "Quantitative Evaluation of Website Quality Dimension for Web2.0 Environment", http://www.sersc.org/journals/IJUNESST/vol4_no4/ 2.pdf, 2011.

[13] samsys, “WEB2.0 FEATURES”, http://www.samsys.com/services/web-20-features.html, 2010.

[14] Om Malik, Ian Murdock’s Weblog, ““'Small pieces loosely joined" and Web2.0", http://ianmurdock.com/cloud/small-pieces-looselyjoined-and-web-20/, 2009.

[15] Karen A. Coombs, "Building a Library Web Site on the Pillars of Web2.0", http://www.infotoday.com/cilmag/jan07/Coombs.sh tml, January 2007.

[16] Tristan Nitot, Paul Rouget, "«Hackability» What it means, why it's important", http://www.slideshare.net/nitot/hackability-what-itmeans-why-its-important, 2010.

[17] Play, http://www.playframework.org/, 2004.

[18] Ori Fishler, "Leveraging Enterprise Web2.0 for competitive advantage", http://edgewatertech.wordpress.com/2008/05/22/lev eraging-e-business-20-for-competitive-advantage/, May 22, 2008.

[19]ARIADNE, "Web2.0: Building the New Library", http://www.ariadne.ac.uk/issue45/miller, October 29, 2005.
[20]Exploring Web2.0 Application, "Web2.0 Patterns: Perpetual Beta -Facebook", http://jaroodi.wordpress.com/2012/04/29/web-2-0patterns-perpetual-beta-facebook/, April 29, 2012.

[21] WebAppRater, "7 key features of Web2.0", http://webapprater.com/general/7-key-features-ofweb-2-0.html, June 29, 2010.

[22] ideum, "Radical Trust", http://ideum.com/blog/2006/08/radical-trust/, 2006.

[23] Wikipedia, "Folksonomy", http://en.wikipedia.org/wiki/Folksonomy, 2011.

[24]Web2.0, "Rich User Experience", http://www.tstiles.com/dms/web20/richuser.html, 2005 .

[25]WIRED, "Web2.0 and the Long Tail", http://www.thelongtail.com/the_long_tail/2005/10/ web_20_and_the_.html, October 01, 2005.

[26]IEEE STD 1061TM-1998 (R2009), "IEEE Standard for a Software Quality Metrics Methodology", http://cow.ceng.metu.edu.tr, 2009.

[27]QUIS, "Questionnaire for User Interaction Satisfaction", http://www.lap.umd.edu/quis/, ver. 7.0, 2000.

[28] Sue F. Abdinnour-Helm, Barbara S. Chaparro, Steven M. Farmer, "Using the End-User Computing Satisfaction (EUCS) Instrument to Measure Satisfaction with a Web Site", http://onlinelibrary.wiley.com/doi/10.1111/j.15405414.2005.00076.x/abstract, 4 April, 2005.

[29]A.M. Aladwani, P.C. Palvia, "Developing and validating an instrument for measuring userperceived web quality", http://www.ugr.es/ focana/dclasif/artuserweb.pdf, 2002.

[30] Jurek Kirakowsk, "Software Usability Measurement Inventory”, http://sumi.ucc.ie/en/, 2011.

[31] Asil Oztekin, Alexander Nikov, Selim Zaim, “An assessment methodology for usability of web-based information systems", http://dl.acm.org/citation.cfm?id=1645587, 12 December 2009.

[32]Cinergix, "Creately”, Draw UML Diagrams, http://creately.com/Draw-UML-and-ClassDiagrams-Online, 2008-2012.

[33] Tobin Harris, “yUML beta”, http://yuml.me/, v0.18, 2011.

[34]Free Statistics and Forecasting Software, "Cronbach Alpha - Free Statistics Software (Calculator)", http://www.wessa.net/rwasp_cronbach.wasp\#output, v1.1.23-r7, 2002-2013. 
Ms. Ambreen Nazir is a MS Scholar as well as Research Associate in the Department of Software Engineering at University of Engineering and Technology Taxila, Pakistan. She graduated from University of Engineering and Technology Taxila in Software Engineering in July 2012. Her areas of interest are Windows Application Development, Web Development, Databases, Software Quality Assurance, Software Project Management, and Software Requirement Engineering.

Ms. Ayesha Raana is a MS Scholar as well as Research Associate in the Department of Software Engineering at University of Engineering and Technology Taxila, Pakistan. She graduated from University of Engineering and Technology Taxila in Software Engineering in July 2012. Her areas of interest are Software Quality Assurance and Operating System.

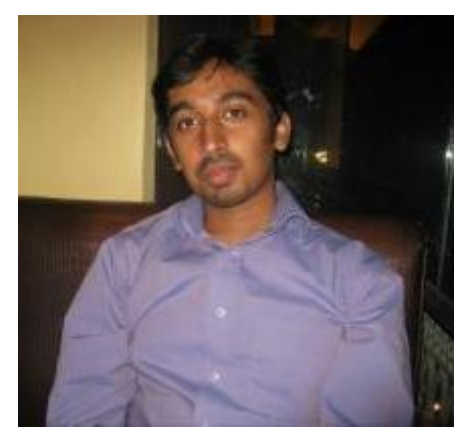

Engr. Ali Javed is serving as an Assistant Professor in the Department of Software Engineering at UET Taxila, Pakistan. He is also a $\mathrm{PhD}$ Scholar in Computer Engineering Department at UET Taxila, Pakistan. He has received his MS degree in Computer Engineering from UET Taxila, Pakistan in February, 2010. He received Chancellor's Gold Medal in MS Computer Engineering degree and became the first MS student in the history of UET Taxila to be awarded Chancellor's Gold Medal. He has received B.Sc. degree in Software Engineering from UET Taxila, Pakistan, in September, 2007. He got 3rd position in Software Batch-2003F in BS Software Engineering degree. His areas of interest are Digital Image Processing, Computer vision, Video Summarization, Mobile Application Development, Software Requirements Engineering, Software Quality Assurance and Software testing. 